\title{
International Partnership Using Remotely Accessed Labs
}

\author{
William Hutzel ${ }^{1}$ and Rudolf Furter ${ }^{2}$
}

\begin{abstract}
An international project between the Mechanical Engineering Technology Department at Purdue University and the HVAC Engineering Department at HTA Lucerne (Switzerland) is testing the limits of the remote access concept by creating a laboratory network that is separated by thousands of miles. Using web-enabled HVAC equipment, U.S. students are determining the performance and return on investment for a heat recovery system that is physically located in Switzerland. The converse is also true, Swiss students have access to a variety of equipment located in the U.S. This remote access project is a good example of a sustainable partnership that adds an international perspective to undergraduate education. Although a relatively small number of students have visited the other institution in person, larger numbers of U.S./Swiss students are recognizing the globalization of engineering practice during routine laboratory work.
\end{abstract}

Index Terms - energy recovery, HVAC, international, laboratory, remote access

\section{DIFFICULTIES FOR NEW INTERNATIONAL EXCHANGES}

This brief overview of the challenging climate for international exchange is not intended to deride the policies of the U.S. State Department. To the contrary, the authors recognize that there are legitimate threats that warrant the increased scrutiny of international students who visit the U.S. The purpose of this narrative is to point out some of the problems facing educators pursuing new exchange programs in a post $9 / 11$ environment. It is important to remember that the primary reasons for conducting an international program (technical and cultural exchange) remain more relevant than ever and outweigh the inconveniences due to heightened security.

Many engineering programs at U.S. universities have well-established programs that allow international exchanges with foreign institutions. Purdue University and Georgia Tech are two prominent examples of large engineering programs with many options for international technical exchanges. [1,2] These programs allow U.S. students to take courses, complete an internship, or conduct research at several international locations and receive credit towards graduation at their home institution. The language barrier, which is a concern for most U.S. students, is usually overcome by using English as the medium for communication. These agreements also typically have reciprocity to allow for international students to visit the U.S. A standard goal is for equal numbers of U.S. and international students to actively participate in the exchange.

The increased scrutiny placed on student travel by the U.S. State Department is having a negative impact on the number of international students traveling to the U.S. Purdue University, which has one of the largest international student populations, has already noted a significant drop in international student applications and enrollment that is at least partially attributed to more stringent enforcement of visa regulations.[3] A recent article in ASEE Prism pointed out that many U.S. engineering programs are facing similar declines and noted that the U.S. is not always the destination of choice for international students.[4]

Purdue University maintains a web-page to help explain the requirements and limitations of different visa options for international students.[5] Exchange students visiting the U.S. for short term projects (less than two weeks) can travel on a tourist visa (B-2). This can be advantageous because a tourist visa is relatively easy to get. Exchange students visiting the U.S for greater than two weeks need to apply for a student visa $(\mathrm{J}-1)$. The $\mathrm{J}-1$ visa requires more interaction between the U.S. consulate in the foreign country and the two universities pursuing the exchange. For example, international students must document that at least $1 / 2$ of their funding for lodging and subsistence (typically around $\$ 500$ per month) comes from non-personal sources.[6] J-1 visas take several months to process and the long lead time can discourage international students.

Articles about the declining number of international students in the U.S. usually focus on the negative implications of reduced manpower for conducting laboratory research. However, the new regulations for international students may also have an impact on educational exchange programs. It is still relatively easy for U.S. students to travel abroad. However, will universities in Europe, Asia, and other parts of the world continue partnering with schools in the U.S. when it can be difficult and time consuming to enter the U.S.?

Despite the hurdles, the overall incentives for international exchange remain stronger than ever. The increasing globalization of technology and engineering practice is impossible to ignore. In the U.S., the Technology Accreditation Commission (TAC) of the Accreditation Board For Engineering \& Technology (ABET) requires that all

\footnotetext{
${ }^{1}$ William Hutzel, Associate Professor, Mechanical Engineering Technology, Purdue University, hutzelw@purdue.edu

${ }^{2}$ Rudolf Furter, Professor, HVAC Engineering, HTA Lucerne, rfurter@hta.fhz.ch 
Session T1A

graduates demonstrate "a respect for diversity and a knowledge of contemporary professional, societal and global issues".[7] Involving students in international projects is an excellent way to help achieve this requirement.

\section{ProJect-BASEd InTERNATIONAL EXCHANGES}

There are many examples of project-based international collaborations. Henry Kraebber, a faculty member in Mechanical Engineering Technology at Purdue University in West Lafayette, has an active exchange program with the University of Kaiserslautern in Germany.[8] Most of the collaboration is conducted over the Internet. One recent project had students in the U.S. and Europe working together on the re-design of a plant layout for a manufacturing facility in Germany. All work on the project was conducted in English, the only language common to all participants. After the re-design was completed, Purdue students visited Germany on a short-term basis to meet with their European colleagues, tour a number of manufacturing operations, and learn about German culture.

Although this exchange project with Germany was very successful, the language barrier was a key challenge that could hinder broader collaborations. German faculty and students communicated well in written and spoken English, but most aspects of the formal German education system (lectures, textbooks, laboratory manuals, etc.) are in the German language. Since it is unlikely that significant numbers of Purdue students will become proficient in German, student exchanges on an academic basis at the University of Kaiserslautern are not likely to prosper unless courses are delivered in English. However, a growing number of courses are being offered in English because they are attractive to students from other countries in Europe who wish to study in Germany.

Collaborative projects that include travel for both U.S. and international students appear to be less common. Professor Eric Calais in the Department of Earth and Atmospheric Sciences at Purdue University in West Lafayette maintains an active exchange with the University of Brest in France. Professor Calais takes a mix of Purdue undergraduate and graduate students to France for two weeks every other summer for a marine geology course where most of the work is conducted on an oceanographic ship. [9] On the intervening summers, French students visit the U.S. to participate in a two week geology trip to the western U.S.

The exchanges with the University of Brest so far have focused on academic courses rather than research projects. However, Professor Calais intends to broaden the scope of the collaboration with the University of Brest to include research in the form of semester-long projects for graduate students. Using international collaborative research as a mechanism to help fund international student exchanges appears to be the most viable way of achieving a sustainable international collaboration. In terms of promoting cultural exchange, it also seems reasonable that both groups of students (U.S. and international) should transfer between the two institutions.

\section{Collaboration BetweEN PURDUE AND HTA LuCERNE}

The international collaboration began in the summer of 2003 , after an initial visit to Switzerland showed striking similarities between HTA Lucerne and Purdue's College of Technology. The faculty at both institutions focus primarily on undergraduate education, but also pursue a variety of applied research projects. Both institutions are developing graduate programs, primarily at the Masters level. There is also a significant overlap in degree programs. Technology degrees in electrical, mechanical, information systems, and building construction are available at both locations.

It is interesting to note that some of the significant differences between HTA Lucerne and Purdue's College of Technology have become compelling reasons for moving this partnership forward. Taken as a whole, Purdue University is much larger ( $>35,000$ students) and more comprehensive than HTA Lucerne $(<1000$ students). Students from HTA Lucerne are attracted to Purdue by the array of academic and cultural activities that are available at a large research university. On the other hand, Purdue students are attracted to HTA Lucerne by the outstanding laboratory facilities that are more widely available to students. The smaller enrollment at HTA Lucerne allows undergraduate students to have more direct access to sophisticated laboratory equipment. Figure 1 also clearly shows why students from Indiana experience a culture shock when visiting the mountains of Switzerland for the first time.

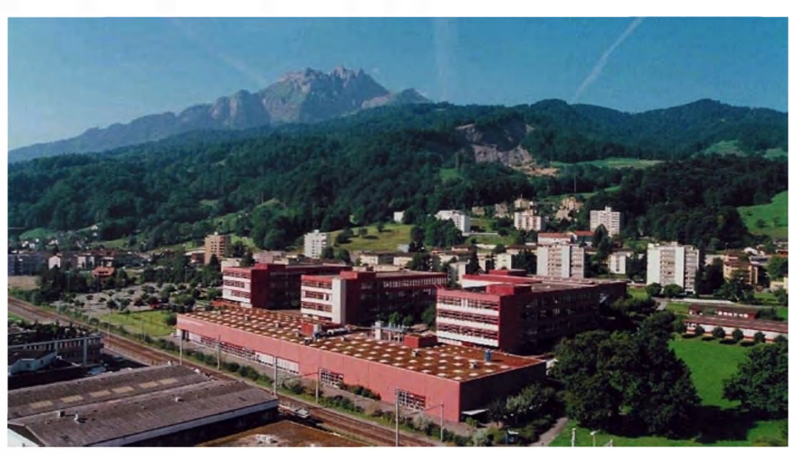

FIGURE 1

HTA Lucerne is at the foot of Mount Pilaturs.

A Memorandium of Understanding signed by Purdue and HTA Lucerne in spring of 2004 creates opportunities for short term faculty/student exchanges to conduct collaborative researcth. The focus on projects, rather than an academic exchange, avoids the language barrier that is common to many international exchanges. Lectures, textbooks, and lab documents at HTA Lucerne are in German, which is incomprehensible to most Purdue Technology studemitss. Fortunately, Swiss faculty and students are competent with Englisth, so that has become the standard for written and verbal communication on collaborative projectss. 
Collaborative projects related to Heating, Ventilating, and Air Conditioning (HVAC) are an attractive area for technology transfer. Due to historically higher energy costs, European expertise with energy efficiency and sustainable building design is generally more advanced than in the U.S. Building codes in the U.S. are just beginning to emphasize sustainable design and energy efficiency during construction and renovation projects. Many of these same requirements are established professional practice in Europe. There are many interesting possibilities for applied research that builds on European HVAC experience to improve buildings in the U.S.

Collaborative HVAC projects emphasize some of the unique strengths of Purdue and HTA Lucerne. The Mechanical Engineering Technology Department at Purdue has expertise with web-enabled building controls and has access to world-class research facilities on the larger Purdue campus. HTA Lucerne has a well-known HVAC Engineering program and an outstanding laboratory facility. Finding common ground for collaborative research is a crucial topic, since research funding is the key to maintaining a long term international collaboration. The small student-lead HVAC project described here should lead to bigger initiatives that improve the performance of commercial buildings.

\section{Heat Recovery Lab Project}

The first international collaborative project was to deploy and evaluate a web-based interface for HVAC equipment physically located in Switzerland. Figure 2 shows the modern air handling unit at HTA Lucerne that was targeted. This equipment is used primarily for teaching in Switzerland, so the final deliverable was a laboratory experiment for Purdue students to evaluate the performance and retum on investment for heat recovery equipment that is an integral part of the air handing unit. The following narrative describes the development process and experimental calculations.

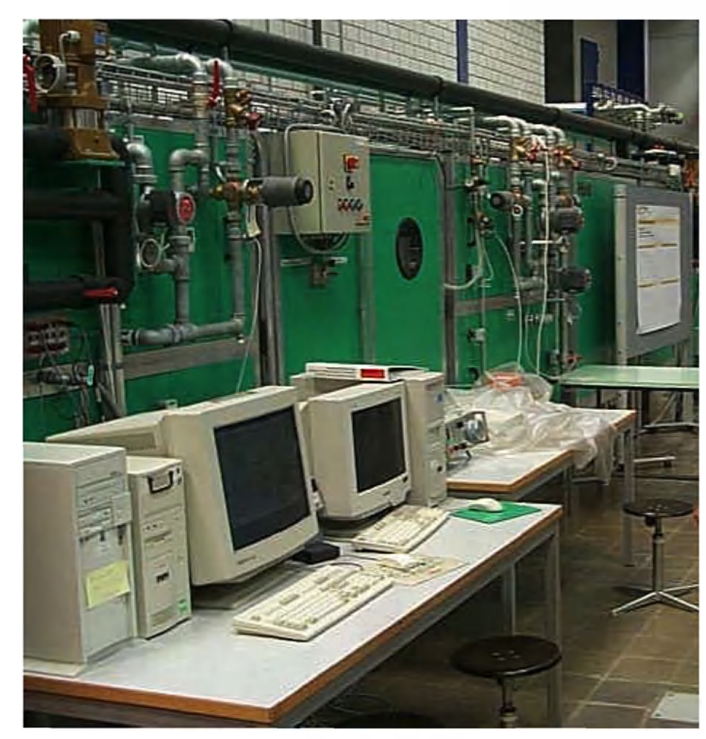

FIGURE 2

WEB ANABLED CONTROLS WERE ADDED TO AN AIR HANDLER.
Table 11 shows that collaborative projects between Purdue and HTA Lucerne are completed on a one year cycle. This time frame is determined by the schedule of diploma projects and graduation for the Swiss students. The initial planning to add a web-enabled control platform to HTA's existing air handling unit started in January 2004. One teleconference and many email exchanges were needed to identify a preliminary scope of work. A Purdue faculty member and students traveled to Switzerland in May of 2004 to finalize some of the project details.

TABLEI

PROJECTS ARE COMPLETED ON A ONE YEAR CYCLE.

\begin{tabular}{|c|c|c|c|c|c|c|c|c|c|c|c|c|}
\hline \multirow{2}{*}{ Project Task } & \multicolumn{12}{|c|}{2004 Calendar Year } \\
\hline & J & $\mathbf{F}$ & M & A & M & $\mathbf{J}$ & $\mathbf{J}$ & A & $\mathrm{S}$ & 0 & $\mathrm{~N}$ & D \\
\hline Selection \& Planning & & & & & & & & & & & & \\
\hline 2. Work in Switzerland & & & & & & & & & & & & \\
\hline 3. Holiday & & & & & & & & & & & & \\
\hline 4. Work in U.S. & & & & & & & & & & & & \\
\hline Project Completion & & & & & & & & & & & & \\
\hline
\end{tabular}

Table $\mathbb{1}$ shows that much of June through September was lost due to summer vacations, but serious work on the project began again in October 2004. An HTA faculty member and students visited Purdue and began developing the software programming and graphic interface for the HVAC equipment. The project was completed after the Swiss students returned to HTA. A remotely accessible laboratory experiment to compute the economic justification for heat recowenny equipment was used in Air Conditioning \& Refrigeration (MET 421) during Spring 2005. An overview of the technical tasks for accomplishing this project is provided next.

The first technical task was to add a web interface to the existing Swiss air handler, which featured building control hardware from Saia-Burgess.[10] Rather than re-designing the control platform from scratch, a control vendor suggested using software called ProMoS NT, which acquires data from the Saia-Burgess controller and makes it available to a server in html formatt[[11]] The ProMoS NT software was developed by MST Systemtecthruik.

The IP address for the Swiss air handler will not be published in this paper. Even though the web page is password protected, many articles have pointed out security concerns when process control equipment is made available over the intemet.[12] There are also concerns about the overall bandwidth of the web-based system. A large number of simultaneous users could slow down system performance for students. Keeping the IP address private will help avoid these potential problems. Since you cannot visit the website yourself, the following narrative provides a guided tour of the most interesting and unique features of the websitte. 
Figure 3 shows a creative way of overcoming the language barrier. After logging on to the secure web server, students choose a language. The website has two graphic interfaces. The two interfaces are similar, except one is in German and the other is in English

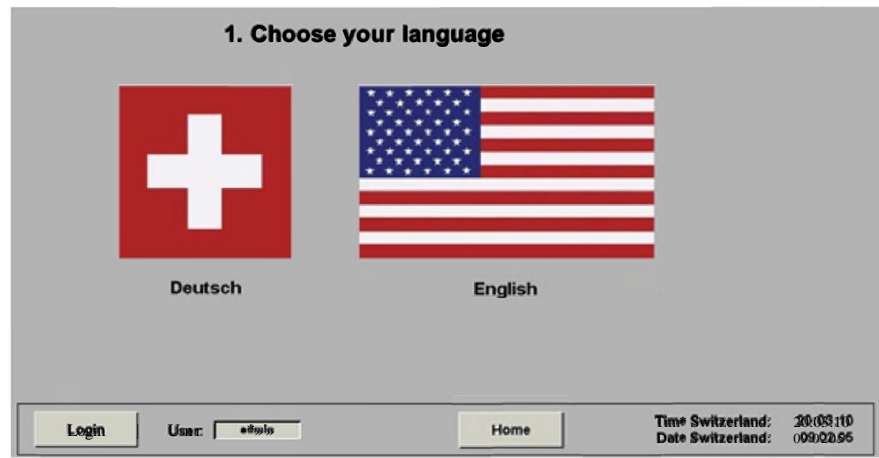

FIGURE 3

THE gRAPHC INTERFACE SUPPORTS TWO LANGUAGES.

Figure 4 shows the top-level graphic interface for the Swiss air handler. The entire system consists of two independent air handling units that are linked by a heat recovery system. Air flowing through fan \#1 is conditioned to resemble the exhaust air leaving a building. The air flowing through fan \#2 is conditioned to resemble typical outdoor conditions for air entering a building. During a remote access lab experiment, Purdue students control the air handlers and collect data to determine the effectiveness (s) of heat recovery.

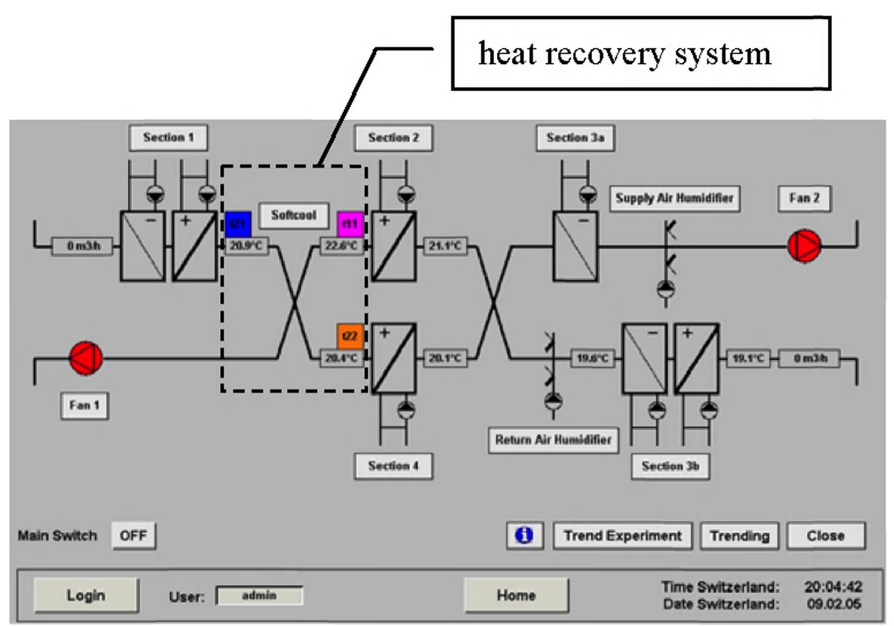

FIGURE 4

A WEB PAGE MONITORS AND CONTROLS THE SWISS EQUIPMENT.

Figure $\mathbf{5}$ is a detailed schematic that identifies temperature sensors at the supply and discharge of the heat recovery system. Equation 1 shows that effectiveness (s) for a flat plate heat exchanger is a simple temperature ratio. The numerator is the beneficial thermal energy transfer for air entering the building. The denominator is the maximum thermal energy available between the two air streams. It should be clear that a larger effectiveness (s) is better because it indicates a larger heat recovery.

$$
\xi=\left(t_{22}-t_{21}\right) /\left(t_{11}-t_{21}\right)
$$

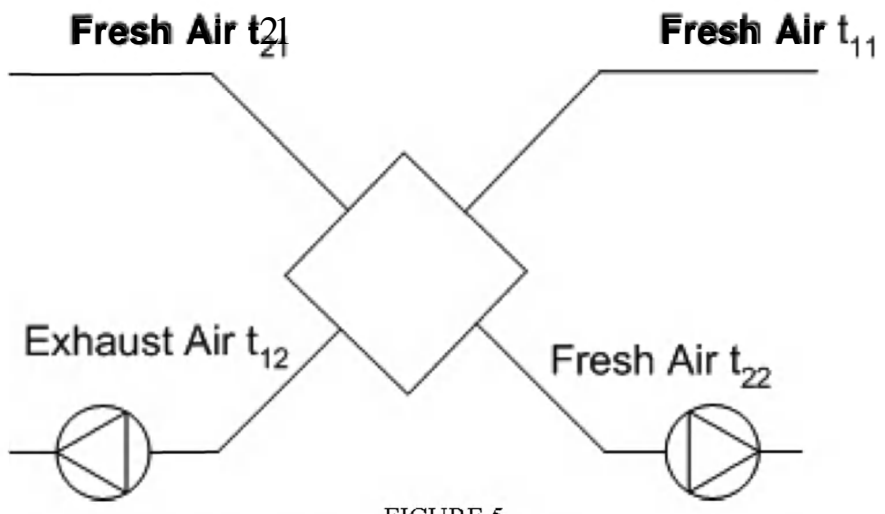

FIGURE 5

EFFECTIVENESS OF HEAT RECOVERY IS CALCULATED FROM EQUATIION 1

While conducting an experiment, Purdue students determine heat recovery effectiveness as a function of airflow rates. Students collect an initial set of temperature data with the supply and exhaust air flows in the range of $3500 \mathrm{~m} 3 / \mathrm{hr}$. Small adjustments to the supply and exhaust air flows are made using variable speed drives. After allowing the air handler to stabilize, students compute new effectiveness values. The data usually confirms that heat recovery effectiveness is relatively constant for small changes in air flow.

Figure 6 is a cumulative frequency diagram for outdoor temperature that is the basis for the return on investment computation. This type of analysis is widely used for energy calculations in the HVAC industry. An overview is presented here, but a more detailed description is available in reference 13 and many other publications. It is important to note that there are many potential variations on these basic calculations. This particular analysis is valid for a relatively small commercial building, where heating and cooling loads vary with the season.

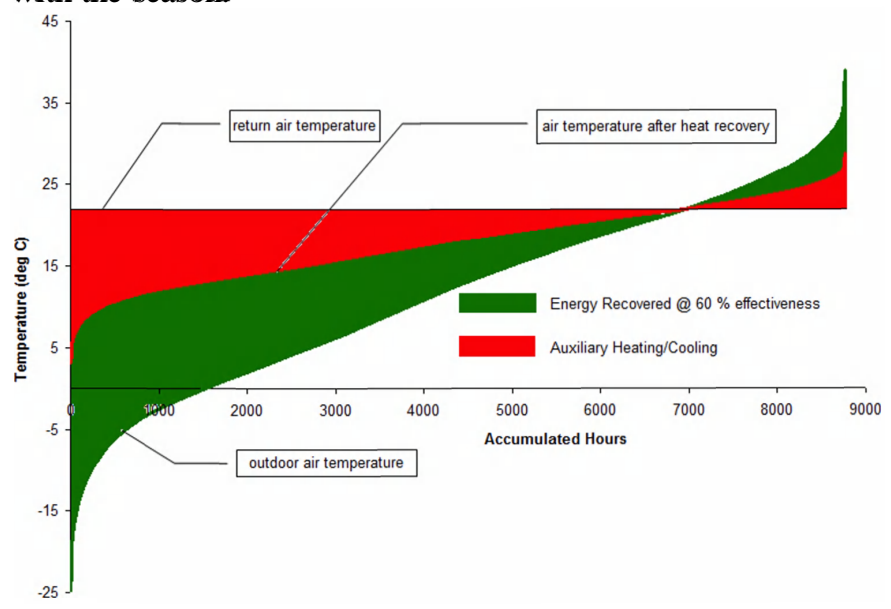

FIGURE 6

ANNUAL WEATHER DATA IS USED TO COMPUTE RETURN ON INVESTMENT.

October 19-22, 2005, Indianapolis, IN 
The historical weather data for the graph is available from the National Oceanic and Atmospheric Administration (NOAA) or the American Society of Heating, Refrigerating, and Air Conditioning Engineers (ASHRAE).[14,15] The vertical axis of the graph is outdoor temperature in degrees Celsius and the horizontal axis is the number of hours in one year. The lower boundary of the curve shows outdoor air temperature on an hourly basis for a typical year in the Midwest U.S. The upper horizontal boundary shows the constant return air temperature for ventilation air leaving the building. The middle curve, at the boundary of the green and red zones, shows the air temperature after a heat recovery system that is $60 \%$ effective.

This temperature graph is particularly useful because the colored zones illustrate heat recovery performance. The area of the green zone is proportional to the energy recovered. The graph clearly shows that heat recovery is very beneficial during cold winter weather, but also helps reduce cooling loads during hot summer weather. Students use a spreadsheet to estimate the magnitude of the green area and convert it into standard energy units (Btu or kW-hr). The area of the red zone is not used for computations but is proportional to the energy for auxiliary heating and cooling to supplement heat recovery.

After evaluating heat exchanger effectiveness and plotting it on a cumulative frequency diagram, the remaining economic calculations are intuitive. Students use a spreadsheet to evaluate equations 2 and 3 shown below. Equation 2 for Annual Energy Savings uses the savings for the energy recovery shown in Figure 6 and deducts the costs of additional fan energy (due to pressure drop across the heat exchanger) and a standard fee for maintenance. Equation 3 for Return on Investment compares the installed cost of heat recovery to annual energy savings. When students are given typical equipment and installation costs, the return on investment is usually around three years. Since the economic payback is relatively short with respect to the life of an air handler, students are able to show that energy recovery is good practice for small commercial buildings located in the Midwest U.S.

$$
\begin{array}{cccc}
\begin{array}{c}
\text { Annual } \\
\text { Energy }
\end{array} & \begin{array}{c}
\text { \$for } \\
\text { Energy }
\end{array} & \begin{array}{c}
\text { F for } \\
\text { Fan }
\end{array} & \begin{array}{c}
\$ \\
\text { for } \\
\text { Savings }
\end{array} \\
\begin{array}{c}
\text { Recovered } \\
\text { Energy }
\end{array} & \text { Maintenance } \\
\begin{array}{c}
\text { On } \\
\text { Investment }
\end{array} & = & \frac{\text { Installed Cost of Heat Recovery }}{\text { Annual Energy Savings }}
\end{array}
$$

\section{IMPACT ON STUDENT LEARNING}

This project has been very successful from the perspective of the faculty and students who had an active role. Additional data has been collected to determine the project's impact on end users, the students at Purdue who run the experiment. Table 2 is the results of a short survey posed to 23 students in Air Conditioning \& Refrigeration (MET 421), a senior-level elective for Mechanical Engineering Technology students. MET 421 students completed the economic analysis of the
Swiss heat recovery system as part of a two hour lab project in March of 2005. After submitting their written lab assignment, students were asked to characterize six statements on a Likert scale of 1 to 5 , with a " 1 " indicating strong disagreement and a " 5 " indicating strong agreement. Table 2 summarizes the survey questions and the median response of the entire class. The survey results will be discussed in terms of the three topic areas on the left column of Table 2.

The first topic targeted student perceptions of web-based data. Did students interpret this heat recovery lab experiment as something more than a computer game? Students accepted the reliability and accuracy of the web-based data (4.0) and indicated that the web-based data was more than a simulation (5.0). These results are preliminary evidence that a carefully designed graphic interface can convey technical data in a realistic and believable format.

The second topic provided feedback about the overall viability of remote labs. Laboratory experiments typically provide direct access to real equipment. How did students react to an experiment conducted entirely at a computer terminal? Students agreed that remote access is a good way to share lab equipment (5.0) and that remote access labs are interesting (4.0). The favorable results from students should encourage educators to consider using web-enabled equipment to enhance instruction for laboratory-based courses.

The third topic focused on the international aspects of the project, which was completed using equipment physically located in a region of Switzerland where German is the preferred language. Students agreed that the remote lab illustrated global aspects of technology (4.0), but also recognized that languages differences can be a barrier for international technical exchange (4.0). Any project that encourages student to think about the globalization of technology is a significant benefit that should be encouraged.

\begin{tabular}{|c|c|c|}
\hline Topic Area & Student Survey Question & $\begin{array}{c}\text { Median } \\
\text { Response }\end{array}$ \\
\hline \multirow{2}{*}{$\begin{array}{c}\text { Perceptions } \\
\text { of } \\
\text { Web Data }\end{array}$} & $\begin{array}{l}\text { 1. The data was trustworthy } \\
\text { in terms of its reliability } \\
\text { and accuracy. }\end{array}$ & 4.0 \\
\hline & $\begin{array}{l}\text { 2. The data was for real } \\
\text { equipment, not the result } \\
\text { of a simulation. }\end{array}$ & 5.0 \\
\hline \multirow[t]{2}{*}{$\begin{array}{l}\text { Viability of } \\
\text { Remote Labs }\end{array}$} & $\begin{array}{l}\text { 3. Remote access is good } \\
\text { way to share lab } \\
\text { equipment. }\end{array}$ & 5.0 \\
\hline & $\begin{array}{l}\text { 4. Remote access labs are } \\
\text { interesting. }\end{array}$ & 4.0 \\
\hline \multirow{2}{*}{$\begin{array}{l}\text { International } \\
\text { Outreach }\end{array}$} & $\begin{array}{l}\text { 5. The heat recovery lab } \\
\text { illustrates technology } \\
\text { transfer on a global scale. }\end{array}$ & 4.0 \\
\hline & $\begin{array}{l}\text { 6. Language differences are a } \\
\text { barrier for international } \\
\text { technical exchange. }\end{array}$ & 4.0 \\
\hline \multicolumn{3}{|c|}{$\begin{array}{l}A \text { " } 1 \text { " indicates strong disagreement and a " } 5 \text { " indicates } \\
\text { strong agreement with the corresponding statement. }\end{array}$} \\
\hline
\end{tabular}

TABLE 2

STUDENTS SUPPORTED REMOTELY ACCESSED LABS.

October 19-22, 2005, Indianapolis, IN 


\section{CONCLUSION}

This remote access lab project has been a good starting point for a new international collaboration between two schools with a common interest in HVAC and energy conservation. It is hoped that this small project will lead to larger collaborations and research funding that is needed to ensure long term sustainability. This project has also demonstrated a creative way to help address one of the more vexing accreditation challenges facing engineering technology programs in the U.S. The recent shift to outcomes based assessment specifically requires that engineering technology programs demonstrate that all graduates have an appreciation for the globalization of engineering practice.

\section{ACKNOWLEDGMENT}

The Partial support for this work was provided by the National Science Foundation's Office of International Science \& Engineering under grant 0427516.

\section{REFERENCES}

[1] International Academic Projects at Georgia Tech, (2005), Georgia Tech, Retrieved March 1, 2005 from http://www.oie.gatech.edu/sa/programs/otheropp.html

[2] International Programs for Mechanical Engineers, (2005), Purdue University, Retrieved March 1, 2005 from http://tools.ecn.purdue.edu/ME/International/

[3] Steckler, Ben, (2004, January 10), "Visa Problems May Hurt International Student Enrollment" Purdue Exponent, January 10, 2005.

[4] Selingo, J., (2005), "Difficult Crossing", ASEE Prism, February 2005, Volume 14, No. 6.

[5] Nonimmigrant visa Classifications (2005), Purdue University, Retrieved March 1, 2005 from http://www.adpc.purdue.edu/Disburse/nonimmclass.htm.

[6] Hammack, M., (2005), Email communication from International Students \& Scholars, Purdue University on January 12, 2005.

[7] Technology Accreditation Commission Criteria (2005), ABET, Retrieved March 1, 2005 from http://www.abet.org/criteria.html.

[8] Kraebber, Henry, (2005), Professor of Mechanical Engineering Technology, Purdue University, Personal Communication, March 8, 2005

[9] University at Sea, (2005), Purdue University, Retrieved February 28, 2005 from http://www.eas.purdue.edu/ ecalais/ubo/

[10] Saia DDC-Plus, (2005), Retrieved March 14, 2005 from http://www.saia-burgess.com/4791/4958/4951/4889/4894.asp

[11] ProMoS NT, (2005), Retrieved March 14, 2005 from http://www.musystec.ch/promosnt/

[12] Bragg, Roberta, (2004), "The Hidden Risks of Process Controls", MCPmag.com, May 2004, Retrieved March 10, 2005 from http://mcpmag.com/columns/article.asp?EditorialsID $=702$

[13] Besant, R.W. and C.J. Simonson, (2000), "Air-to-air energy recovery", ASHRAE Journal 42(5):31-42.

[14] NOAA Engineering Weather Data, (2005), Retrieved March 11, 2005 from http://www.ncdc.noaa.gov/oa/climate/climateresources.html

[15] ASHRAE Weather Data, (2005), Retrieved March 11, 2005 from http://www.bae.uky.edu/ colliver/ASHRAE_TC-4.2/research.htm 